\title{
The Message of the COVID Pandemic
}

\author{
Giulio M. Mari, MD, ${ }^{1}$ Tommaso Fossali, MD, ${ }^{2}$ Giampaolo Ugolini, MD, ${ }^{3}$ \\ Marco Maltoni, MD, ${ }^{4}$ and Giancarlo Cesana, $\mathrm{MD}^{5}$
}

\section{Dear Editor}

"Life is a terminal disease and it is sexually transmitted." With this eye-catching sentence, Michael Cleese highlighted the mission of medicine during a BBC telecast. ${ }^{1}$ As life cannot be cured, that is death cannot be defeated, the primary role of medicine is palliative. Let us be absolutely clear, to avoid a common misunderstanding. The world palliation derives from pallium the mantle that St. Martin split with the sword in order of covering a naked beggar that turned out to be God. ${ }^{2}$ Palliation means to make life worth living, which includes any effort to prolong life. ${ }^{3}$ We refuse any reference to pallium the shroud that covers the casket at the church funeral. According to this interpretation, palliation is just a masquerade to conceal the ugly aspects of agony and death.

If the mission of medicine is palliation, the goal of medicine is healing rather than curing. Healing means to come to terms with one's condition, the ability to treasure one's sufferance and one's death. Although cure is seldom possible, healing is always possible. ${ }^{4}$ Unfortunately, the very advances that have allowed us to conquer previously uncurable diseases, such as some forms of metastatic cancer, might have contributed to shift the focus of our profession toward a race with death and distracted us from our primary goal: to heal.

The current pandemic has revealed the limitations of medical science when it comes to curing and has reminded the practitioners that "there is a time to be borne and a time to die" as the priestly writer of the book of Quoleth stated 2500 years ago. ${ }^{5}$ If death is the final enemy, the whole humanity has been doomed since its beginning as there is no escape from death. Death can be conquered when we are able to coopt it in our life. To identify its meaning.

The practitioner has multiple and different opportunities to do that. The first and the simplest of course is to do everything possible for the relief of pain and suffering. Important to keep the two terms distinct: there may be pain without suffering (e.g., the fatigue a climber experiences in opening a new route on the mountain). And there may be suffering without physical pain, such as the forced solitude of older individuals in the nursing homes. Even when the most advanced techniques of pain control are not available, the practitioner might be able to relieve suffering. There are in the literature two very impressive descriptions of plague epidemics. During the plague of Milan in the 1600, the main focus of the capuchin priests assigned to assist the dying was to relieve their loneliness, listening to their unconfessed wishes as described by Alessandro Manzoni in "the Betroths." "In "The plague" the Nobel prize winner Albert Camus outlines the character of Dr. Bernard Rieux who found the meaning of his profession in comforting the dying. Unable to believe in God, Dr. Rieux asked whether there may be such a thing as an "atheist saint.",

These considerations should comfort health care professionals around the world asked to care for Covid-19 patients at the risk of their own life. Is it worthwhile to manage death when there is no hope of cure, when the only effect of the intervention is comforting another person and compromise at the same time one's own and one's family health and livelihood? Is it right to risk your own and your children's lives to manage such a situation? Anger and frustration, although legitimate, may only enhance the sense of powerlessness and despair. To survive this epidemic unscathed, indeed confirmed in our mission, we need to look at COVID-19 as an opportunity to bring healing, not just to the sick but to the society as a whole, disassembled by the plague. We may recoil from this task and regret forever the missed opportunity. Or we may embrace the task embedded in our mission, recognize our unique talents, and confirm John Donne's words: "No man is an island...... each death diminishes me... don't send to ask for whom the bell tolls: it tolls for thee., 8

\section{References}

1. Cleese M: All Change (The Management of Change) Part One, Change for the Better, BBC Late One Night telecast, 1988.

\footnotetext{
${ }^{1}$ General Surgery Department, ASST Monza, Desio Hospital, Lombardia, Italy.

${ }^{2}$ Department of Anesthesiology and Intensive Care, ASST Fatebenefratelli-Sacco, Luigi Sacco Hospital, Polo Universitario, University of Milan, Milan, Italy.

${ }^{3}$ Colorectal Surgery, Department of Surgery, Ospedale degli Infermi, Faenza, Italy.

${ }_{5}^{4}$ Palliative Care Unit, Istituto Scientifico Romagnolo per lo studio e la cura dei tumori (IRST) IRCCS, Meldola, Italy.

${ }^{5}$ Research Center on Public Health University of Milano Bicocca, Monza, Italy.
} 
2. Saint Martin: Gives Is Mantle to a Poor. The Pallium, Jacopo da Ponte, Museo Civico di Bassano, Italy, 1580.

3. Byock I: The Prospective of Death at the End of Life. Riverhead Book, 1997.

4. Egnew TR: The meaning of healing: Transcending suffering. Ann Fam Med 2005;3:255-262.

5. Holy Bible, Qoheleth Book (Ecclesiastes) 3:1-11.

6. Manzoni A: The Betrothed: The Great Plague of Milan, Chapter 31, 1827.

7. Camus A: The Plague, Chapter 4, 1947.

8. Donne J: No Man Is an Island. Meditation XVII. Satyre III, 1598.
Address correspondence to: Giulio M. Mari, MD

General Surgery Department ASST Monza Desio Hospital Via Mazzini 1 Lombardia 20832

Italy

E-mail: giul_mari@yahoo.it 